\title{
Análise da viabilidade econômica e financeira da produção de leite em propriedade familiar: estudo de caso do Rancho Pacheco, RJ
}

\begin{abstract}
Mirella Suhett Tito Graduação em andamento em Engenharia de Agronegócios pela Universidade Federal

Fluminense - UFF Rua Miguel de Frias, 9. Icaraí. Niterói/RJ. CEP: 24.220-900 E-mail: mirellasuhett@id.uff.br

Afonso Aurélio de Carvalho Peres Doutorado em Produção Animal pela Universidade Estadual do Norte Fluminense Darcy Ribeiro- UENF Professor da Universidade Federal Fluminense - UFF Rua Miguel de Frias, 9. Icaraí. Niterói/RJ. CEP: 24.220-900 E-mail: afonsoaurelio@id.uff.br
\end{abstract}

\section{RESUMO}

Para realização deste trabalho, foi analisada a atividade pecuária desenvolvida em uma propriedade rural de produção leiteira, considerando os indicadores técnicos e financeiros, durante o período compreendido entre os anos de 2011 e 2015. Os dados foram coletados mensalmente a partir do uso de planilhas eletrônicas construídas no MS-Exce ${ }^{\circledR}$, considerando-se todos os itens de produção envolvidos na atividade leiteira. Os itens foram classificados em entradas e saídas para a composição do fluxo de caixa e realizou-se a análise econômico-financeira para a determinação dos indicadores econômicos de rentabilidade: valor presente líquido e taxa interna de retorno. Por apresentar VPL positivo, a atividade leiteira foi viável financeiramente. Devido à rentabilidade financeira $(5,3 \%$ ao ano) ser menor que a taxa mínima de atratividade (6,87\% ao ano), a atividade não foi atrativa para investimento. Para a identificação dos itens de maior influência nos resultados dos indicadores econômicos da atividade, realizou-se a análise de sensibilidade, promovendo-se uma variação dos preços de mercado dos itens de produção que compõem o fluxo de caixa, sempre na condição desfavorável ao pecuarista na ordem de $10 \%$. O preço de aquisição da terra foi o item de maior impacto nos resultados econômicos da atividade, seguido pelo preço de comercialização do leite. $\mathrm{O}$ risco financeiro da atividade leiteira é considerado alto.

Palavras-chave: Agronegócio do leite. Análise de sensibilidade. Fluxo de caixa. Taxa interna de retorno. Valor presente líquido.

Analysis of the economic and financial viability of milk production in family property: case study of Rancho Pacheco, RJ 
Análise da viabilidade econômica e financeira da produção de leite em propriedade familiar:

estudo de caso do Rancho Pacheco, RJ

Mirella Suhett Tito, Afonso Aurélio de Carvalho Peres

\section{ABSTRACT}

To perform this work, the livestock activity developed in a rural dairy farm was analyzed, considering the technical and financial indicators, during the period from 2011 to 2015. Data were collected monthly, from the use of spreadsheets built in MS-Excel®, considering all the production items involved in the dairy activity. The items were classified as inflows and outflows for cash flow composition and the economic and financial analysis was performed to determine the economic indicators of profitability: net present value and internal rate of return. By presenting positive NPV, the dairy activity was financially viable. Because the financial return (5.3\% per year) is lower than the minimum attractiveness rate $(6.87 \%$ per year), the activity was not attractive for investment. To identify the items with the greatest influence on the results of the economic indicators of the activity, a sensitivity analysis was performed, promoting a variation of the market prices of the production items that compose the cash flow, always in the unfavorable condition to the cattle farmer in $10 \%$ order. The acquisition price of land was the item with the greatest impact on the economic results of the activity, followed by the price of milk commercialization. The financial risk of dairy activity is considered high.

Keywords: Agribusiness of milk. Cash flow. Internal rate of return. Net present value. Sensitivity analysis.

\section{INTRODUÇÃO}

$\mathrm{Na}$ Cadeia do Agronegócio leiteiro, tem-se o leite como importante produto na formação de renda de muitos produtores rurais e, por consequência, na fixação do homem no campo. Portanto, a produção familiar, assim como outras estruturas que têm como objetivo o lucro, é importante haver o planejamento, o gerenciamento e análises financeiras que projetem a atividade a um resultado desejado. A Engenharia Econômica permite analisar e compreender os fatores dos processos inerentes à produção. Para tanto, são calculados os valores que compreendem a receita e a despesa da atividade, de forma a gerar os indicadores que permitem avaliar a produção e verificar sua viabilidade e rentabilidade.

A produção bovina de leite no Brasil atingiu 35 bilhões de litros no ano de 2015 , segundo dados apresentados pela Pesquisa Pecuária Municipal (IBGE, 2016). A região Sudeste é responsável por $34 \%$ da produção nacional, ficando atrás somente da região 
Análise da viabilidade econômica e financeira da produção de leite em propriedade familiar:

estudo de caso do Rancho Pacheco, RJ

Mirella Suhett Tito, Afonso Aurélio de Carvalho Peres

Sul $(35,2 \%)$, sendo observada uma queda na produção da região Sudeste, na ordem de $1,9 \%$ em relação ao ano de 2014, ao passo que a região Sul apresentou um crescimento na produção leiteira na ordem de $0,9 \%$, no mesmo período (EMBRAPA, 2017).

A pecuária leiteira é de fundamental importância para o Agronegócio Brasileiro, tendo em vista que a atividade leiteira participa na formação da renda de grande número de produtores, além de ser responsável por elevada absorção de mão de obra (contratada e familiar), propiciando a fixação do homem no campo (Campos \& Piacenti, 2007).

De acordo com Lima Júnior (2014), os produtores brasileiros em sua maioria, possuem uma pequena produção de leite, com menos de 100 litros/dia, em média. No estado do Rio de Janeiro, cada produtor produz, em média, 98 litros/dia. Com uma disponibilidade per capita de 33,7 litros de leite, a produção Fluminense não é suficiente para abastecer uma população de 16 milhões de habitantes. Portanto, produzir leite neste estado dá ao produtor boas oportunidades de comercialização, proporcionando preços mais atrativos. A produção leiteira no estado está mais concentrada nas regiões Noroeste e Sul Fluminense e, segundo o Censo do IBGE, o estado do Rio de Janeiro tem aproximadamente 15.000 produtores (IBGE, 2016).

Independentemente da classificação de cada setor produtivo, de suas atribuições, níveis tecnológicos e da renda obtida, a agricultura familiar reúne aspectos importantes como: a família, o trabalho, a produção e as tradições culturais. A mulher assumiu um papel muito importante em propriedades de economia familiar, sendo diagnosticado que em cerca de um terço dos estabelecimentos essa participação é recorrente e ativa com trabalhos relacionados com a ordenha dos animais, fabricação de derivados, trato dos animais, manejo de bezerros e limpeza dos utensílios, pode ser considerada como aquela que, ao mesmo tempo em que é proprietária, assume os trabalhos no estabelecimento (Zoccal \& Souza, 2005).

O tripé que sustenta e proporciona equilíbrio aos produtores de leite é formado por: planejamento, gerenciamento e análises do custo de produção. Assim, diante da 
Análise da viabilidade econômica e financeira da produção de leite em propriedade familiar: estudo de caso do Rancho Pacheco, RJ Mirella Suhett Tito, Afonso Aurélio de Carvalho Peres

elevada concorrência, de incertezas e de lucro em que os produtores de leite estão inseridos, eles serão auxiliados nas decisões a serem tomadas para a continuidade da atividade.

A baixa qualificação gerencial dos agricultores para a produção leiteira, a pouca disponibilidade de tecnologias adequadas à realidade da agricultura familiar e as carências de assistência técnica permanente são fatores que, segundo Altafin, Pinheiro, Valone e Gregolin (2011) dificultam as mudanças necessárias para o crescimento do setor lácteo e o estímulo à alta no preço do produto. Para tanto, podemos verificar a necessidade de melhoria das práticas gerenciais, juntamente com os índices de produtividade e com a capacitação para produção e o controle da qualidade do leite, bem como desenvolver novas formas de relacionar os diversos setores do segmento, buscando melhor alternativa para fortalecer e ganhar mercados, promovendo o crescimento do setor lácteo brasileiro.

Assim, a Engenharia Econômica nos permite analisar e compreender os fatores e processos inerentes à produção e à atividade leiteira. À medida que valores são gerados a partir do fluxo de caixa, os quais manifestam o valor do dinheiro no tempo, torna-se possível a compreensão de fatores gerenciais que influenciam nos resultados obtidos com a exploração leiteira.

Para que a pecuária leiteira seja competitiva, é de extrema importância que se avaliem os resultados obtidos a partir de melhorias geradas em todas as etapas que envolvem a produção leiteira e que esses resultados possam responder aos investimentos tecnológicos realizados, tais como: aquisição de tanque de expansão para garantir a qualidade do leite e a implantação de cerca elétrica na subdivisão de piquetes, melhorando o manejo da pastagem e aumentando a produção de volumosos de melhor qualidade para alimentação do rebanho bem como analisar a resposta mediante as melhorias em todos os processos produtivos.

Diante da insatisfação do produtor rural pelo preço recebido no litro de leite comercializado, o presente estudo teve como objetivo analisar economicamente a atividade leiteira da propriedade de economia familiar na Região Sul do estado do Rio 
Análise da viabilidade econômica e financeira da produção de leite em propriedade familiar: estudo de caso do Rancho Pacheco, RJ Mirella Suhett Tito, Afonso Aurélio de Carvalho Peres

de Janeiro, verificando a saúde econômica, bem como identificando os itens de maior influência na atividade, o que permite a tomada de decisão no gerenciamento da atividade.

\section{REFERENCIAL TEÓRICO}

\subsection{Análise da viabilidade econômico-financeira}

De acordo com Peres, Vásquez, Souza, Coelho da Silva, Villela e Santos (2009), o uso de ferramentas da Engenharia Econômica é imprescindível na avaliação de sistemas de produção animal nos dias de hoje, pois a competitividade entre os diversos setores do Agronegócio é maior a cada dia. A análise da viabilidade econômica, com o uso de indicadores econômicos de rentabilidade (Valor Presente Líquido, Taxa Interna de Retorno e Payback descontado), auxilia a possibilidade de argumentação a respeito das possíveis melhorias nos índices zootécnicos e econômicos de uma atividade pecuária, objetivando o aumento da rentabilidade para os produtores familiares, respeitando as normas de boas práticas na produção animal e 0 respeito ao meio ambiente.

A área de custos propicia aos gestores a utilização de algumas ferramentas para auxiliar no processo de tomada de decisão e, consequentemente, contribuir para o desenvolvimento de diferencial no mercado competitivo. Para Slack, Chambers, Johnston e Betts (2008), os objetivos de desempenho são todas as operações que agregam valor aos clientes e contribuem para a competitividade, satisfazendo os requisitos de seus clientes. Os autores afirmaram ainda que existem cinco aspectos de desempenho das operações, sendo eles: a qualidade, a velocidade, a confiança, a flexibilidade e os custos que afetarão a satisfação do cliente e a competitividade do negócio.

A análise de custos é uma ferramenta estratégica no processo decisório, sendo indispensável na execução de diversas tarefas gerenciais, tais como formação de preços, otimização da produção, valorização de estoques etc. (Guimarães Neto, 2008). 
Análise da viabilidade econômica e financeira da produção de leite em propriedade familiar: estudo de caso do Rancho Pacheco, RJ Mirella Suhett Tito, Afonso Aurélio de Carvalho Peres

A análise de viabilidade econômico-financeira envolve o planejamento e a gestão dos recursos materiais, humanos, financeiros, de uma atividade onde se projeta, se quantifica e busca alcançar os indicadores produtivos e financeiros desejados, garantindo a rentabilidade financeira. Permite compreender a saúde financeira da atividade, bem como identificar pontos que devem ser corrigidos. Os resultados econômicos obtidos auxiliam na tomada de decisão do investidor se deseja manter a atividade, parar ou expandir. Os indicadores econômicos de rentabilidade, valor presente líquido e taxa interna de retorno são aqueles considerados de fácil entendimento e que permitem identificar se a atividade está sendo viável ou não financeiramente, bem como se a rentabilidade econômica obtida é atrativa ou não para investimento, considerando sempre uma taxa mínima de atratividade obtida em outros investimentos disponíveis no mercado. Quando o VPL apresenta-se positivo, tem-se uma atividade viável financeiramente, pois as receitas advindas com a exploração estão sendo suficientes para cobrir os custos de produção envolvidos, ao passo que, se for negativo, o investidor inicia um processo de descapitalização. Já para a rentabilidade, se esta apresentar-se superior à taxa mínima de atratividade, o investidor deve aproveitar o bom momento da atividade, ao passo que, se esta for menor, ele deve procurar outros investimentos disponíveis no mercado, pois a atividade não está sendo atrativa para investir.

\subsection{Sistema de produção leiteira}

O desenvolvimento da agroindústria familiar permite visualizar a viabilidade econômica do meio rural, refletindo na permanência do homem e sua família no campo. De acordo com Araújo (2007), agroindústrias são as unidades empresariais em que ocorrem as etapas de beneficiamento, processamento e transformação de produtos agropecuários in natura até a embalagem, prontos para comercialização.

Em uma agroindústria, a quantidade a produzir estará inicial e fortemente ligada à decisão do que produzir, à área disponível (máximo possível) e à demanda ou restrições do mercado, isto é, quantidade recomendável ou contratada (Batalha, 2009). 
Análise da viabilidade econômica e financeira da produção de leite em propriedade familiar: estudo de caso do Rancho Pacheco, RJ Mirella Suhett Tito, Afonso Aurélio de Carvalho Peres

De acordo com Batalha (2009), a produção de bens agroalimentares há várias especificidades que podem afetar positivamente ou não os processos produtivos, como (a) sazonalidade de disponibilidade de matéria-prima: grande parte das matérias primas está sujeita a regimes de safra e entressafra; (b) variações de qualidade de matériaprima: variações climáticas e de técnicas de manejo podem ter impactos profundos na qualidade final do produto transformado; (c) perecibilidade da matéria-prima: grande parte dos produtos transformados nas agroindústrias deve ser manufaturada rapidamente após a colheita e distribuída ao mercado; (d) sazonalidade do consumo: variações de demanda segundo datas específicas ou variações climáticas nas estações do ano; (e) e a perecibilidade dos bens especiais agroalimentares: a maioria dos produtos processados apresenta alto grau de perecibilidade.

\subsection{Gestão financeira agroindustrial}

Para Gomes (2003), o tripé que sustenta e proporciona equilíbrio aos produtores de leite é formado por: planejamento, gerenciamento e análises do custo de produção. Assim, diante da elevada concorrência de incertezas e de lucro em que os produtores de leite estão inseridos, eles serão auxiliados nas decisões a serem tomadas para a continuidade da atividade.

A baixa qualificação dos agricultores para a produção leiteira, a pouca disponibilidade de tecnologias adequadas à realidade da agricultura familiar e as carências de assistência técnica, segundo Altafin et al. (2011), é uma condição que dificulta mudanças no setor lácteo e o estímulo à alta no preço do produto.

Para tanto, podemos verificar a necessidade de melhoria das práticas gerenciais, juntamente com os índices de produtividade e com a capacitação para produção - controle da qualidade do leite, bem como desenvolver novas formas de relacionar os diversos setores do segmento, buscando melhor alternativa para fortalecer e ganhar mercados. 
Análise da viabilidade econômica e financeira da produção de leite em propriedade familiar: estudo de caso do Rancho Pacheco, RJ Mirella Suhett Tito, Afonso Aurélio de Carvalho Peres

Assim, a Engenharia Econômica nos permite analisar e compreender os fatores e processos inerentes à produção, à medida que valores são gerados a partir do fluxo de caixa, os quais manifestam o valor do dinheiro no tempo.

Silva (2013) destacou que o consumo de leite para a criação de bezerros representa um custo e deve ser compreendido nos controles administrativos. Para uma pequena propriedade em que a atividade leiteira é o principal produto, é necessário o acompanhamento constante, com descrição dos custos variáveis e despesas gerais, custos fixos, cálculo de todas as receitas relacionadas com a atividade e determinação do custo de produção de um litro de leite. Assim o produtor pode obter dados mensais importantes para a tomada de decisão.

De acordo com Resende (2010), os indicadores zootécnicos de produção de leite por unidade lactante e mão de obra por área são utilizados para monitorar e avaliar a eficiência financeira da atividade nas fazendas leiteiras, pois interferem nas decisões e podem envolver vários fatores, como investimentos em tecnologia, alterações na composição da alimentação de animais, regularização das pastagens, e impactam em toda a estrutura de uma propriedade que depende da produção do leite. Para isso, é importante o uso de tecnologias viáveis para a produção leiteira, pois segundo Carvalho, Ramos e Lopes (2009), cada propriedade apresenta características e peculiaridades que irão definir o seu próprio centro de custos e a partir dos resultados obtidos, auxiliar os produtores na tomada de decisão.

\section{METODOLOGIA}

\subsection{Material}

O trabalho foi desenvolvido em uma propriedade leiteira de agricultura familiar. Para a caracterização da atividade leiteira, foram realizadas visitas periódicas, bem como entrevistas com o produtor e sua família, a fim de levantar as informações necessárias para a realização da análise financeira. Foi realizado o inventário, coletaram-se os dados zootécnicos e econômicos para, diante das informações, ser 
Análise da viabilidade econômica e financeira da produção de leite em propriedade familiar: estudo de caso do Rancho Pacheco, RJ Mirella Suhett Tito, Afonso Aurélio de Carvalho Peres

possível a compreensão do funcionamento sistêmico da atividade. No levantamento das informações para construção do fluxo de caixa, foi considerado o rebanho, a produção de leite, a alimentação fornecida, o manejo sanitário e reprodutivo adotados. Foram considerados detalhadamente, o uso da mão de obra disponível e as atividades realizadas na propriedade, bem como as tecnologias adotadas na atividade e a renda obtida com a comercialização dos produtos e subprodutos.

O estudo foi realizado durante o período de avaliação do sistema produtivo compreendido entre os anos de 2011 e 2015, com o acompanhamento mensal das atividades realizadas, bem como a comercialização do leite produzido. A propriedade está localizada na cidade de Volta Redonda, estado do Rio de Janeiro, sendo as suas coordenadas cartográficas: $22^{\circ} 27^{\prime} 17^{\prime \prime}$ de latitude Sul e $44^{\circ} 6^{\prime}$ ' $11^{\prime \prime}$ de longitude Oeste.

A propriedade possui uma área total de 16,7 ha, de modo que a alimentação fornecida aos animais foi cultivada em 5,7 ha. Nesse total, foram produzidas pastagens cultivadas durante $\mathrm{o}$ ano todo e forrageiras para fornecimento, como suplementação volumosa, durante o período outono-inverno. A área de pastagens (3,2 ha) compreendeu o cultivo de capim-braquiária ( $1,5 \mathrm{ha})$, pastagem de capim-angola $(0,9$ ha) e pastagem de capim-giggs ( $0,8 \mathrm{ha})$. Na área destinada à produção de volumosos para a suplementação alimentar (2,0 ha), realizou-se o cultivo de capim-Napier (0,7 ha), capim-Cameroon (0,8 ha) e Canavial (0,5 ha). Ainda tem-se 0,5 ha destinado aos corredores de acesso e áreas de descanso aos animais.

Do total (16,7 ha), têm-se ainda as áreas destinadas às moradias, instalações (curral, sala de ordenha, almoxarifado, garagem,...), pomares, horta etc., que compreendem 2,1 ha, e o restante (8,9 ha) foi destinado à área de reserva legal.

A mão de obra utilizada na atividade leiteira é exclusivamente familiar (3 pessoas), sendo as atividades empregadas divididas entre os membros da família, em que se observou que os homens (2 pessoas) ficaram responsáveis pela administração da propriedade, manejo do rebanho no campo, colheita de volumosos para o trato de animais, realização das práticas de manejo sanitário e reprodutivo do rebanho, enquanto que a mulher (1 pessoa) auxiliou no manejo da ordenha, bem como na 
Análise da viabilidade econômica e financeira da produção de leite em propriedade familiar: estudo de caso do Rancho Pacheco, RJ Mirella Suhett Tito, Afonso Aurélio de Carvalho Peres

limpeza de máquinas, equipamentos, tanque de resfriamento utilizado na produção de leite. Outras atividades foram registradas em complementação à atividade leiteira, o que ocorre na maioria das propriedades rurais de agricultura familiar. Dentre as atividades, foram observadas a venda de leite para a cooperativa, a comercialização de animais inservíveis à atividade e à venda de esterco. Outras fontes de renda que a família ainda obteve, durante o período de estudo, foram com a reciclagem de objetos descartados, a prestação de serviços técnicos, como mochação de animais para terceiros e o aluguel de bem pessoal (casa) para outros interessados.

No sistema de produção durante o período primavera-verão, com o manejo de pastagem adotado, foi possível a obtenção de até $15 \mathrm{UA} /$ ha para a pastagem de capimgiggs, $12 \mathrm{UA} /$ ha para a pastagem de capim-Angola e de $8 \mathrm{UA} /$ ha para a pastagem de capim-braquiária, uma vez que se adotou o pastejo rotacionado com a intensificação das áreas (20 piquetes), mediante o uso de corretivos e fertilizantes durante o período.

$\mathrm{O}$ uso de concentrados ocorreu mediante o fornecimento de ração balanceada formulada na propriedade e fornecida diariamente no cocho, sendo que cada lote de vacas recebeu a quantidade de acordo com o volume de leite produzido. $\mathrm{Na}$ formulação, fez-se uso de ingredientes como: farelo de soja, fubá, polpa cítrica, farelo de algodão, entre outros, adicionando-se à composição o sal mineral comercial.

No manejo reprodutivo, adotou-se a monta natural com utilização de reprodutor (1) da raça holandesa. As matrizes (12) apresentaram grau de sangue variando entre 1/2 e 7/8, mestiços da raça Girolando. O intervalo de partos foi de 14 meses. Do total de 24 animais pertencentes ao rebanho, constataram-se ainda 10 fêmeas bovinas, entre bezerras e novilhas, e 1 garrote. A composição do rebanho oscilou entre os quatro anos de acompanhamento, porém esta distribuição de animais em categorias foi a que melhor representou o efetivo de rebanho.

A taxa de lactação, durante o período primavera-verão, foi de $83,3 \%$ e, para o período outono-inverno, foi de $66,7 \%$.

No manejo sanitário, observou-se que o calendário oficial de vacinação do estado do Rio de Janeiro é realizado. Dentre as vacinações adotadas no controle 
Análise da viabilidade econômica e financeira da produção de leite em propriedade familiar: estudo de caso do Rancho Pacheco, RJ Mirella Suhett Tito, Afonso Aurélio de Carvalho Peres

sanitário do rebanho, estão a febre aftosa, brucelose, raiva e carbúnculo. Foi observada a realização periódica dos exames contra brucelose e tuberculose, atendendo as exigências sanitárias para a comercialização do leite. No controle de parasitas, o produtor certifica-se de comprar e utilizar medicamentos contra a incidência de carrapatos e bernes. Foi observado que o produtor não tem um bom conhecimento no uso de produtos veterinários, bem como forma de aplicação, dosagem, cuidados sanitários após a utilização dos mesmos, fato este que ocasionou um período em que a perda de leite por presença de antibiótico foi constatada, o que reduziu a renda da atividade por desconhecimento de períodos de carência na comercialização do leite produzido.

A produção média de leite foi de 133,0 litros/dia para o período primaveraverão, enquanto que, para o período outono-inverno, observou-se uma produção de 123,2 litros/dia, permitindo assim um fornecimento constante à empresa captadora de leite. Do total de vacas em lactação, analisou-se a produção média diária de leite, que foi na ordem de 13,3 litros/animal (10 vacas) durante o período primavera-verão e de 15,4 litros/animal (8 vacas) no período outono-inverno. Diante disso, estimou-se a produção média do rebanho, que foi de 10,9 litros de leite/vaca/ano e a produção total por área, de 14,6 litros/ha/ano. A produção média total foi de 48.346,28 litros de leite/ano e, em todo processo produtivo, o leite produzido foi resfriado e comercializado in natura, tendo sido enviado a uma Cooperativa de laticínios localizada na região SulFluminense.

Na pecuária leiteira, para garantir a eficiência na atividade, é indicado controle relacionado com a baixa contagem de células somáticas presentes no leite e alta produtividade por área do rebanho. Visando ao aumento da receita bruta da atividade, produzir leite com maior teor de sólidos (gordura e proteína), aliado aos melhores indicadores de sanidade e higiene do rebanho, contribui para elevar a qualidade da matéria-prima desde a base da cadeia produtiva, fato este que foi observado a partir de melhorias no controle sanitário do rebanho e no manejo da ordenha, com a utilização de práticas de higiene e produtos com maior eficiência no combate a enfermidades e 
Análise da viabilidade econômica e financeira da produção de leite em propriedade familiar: estudo de caso do Rancho Pacheco, RJ

Mirella Suhett Tito, Afonso Aurélio de Carvalho Peres

contaminação. O controle na incidência de mastite bovina passou a ser um dos principais fatores no processo produtivo a ser monitorado, pois foi observado o elevado custo com a aquisição de medicamentos e tratamento de animais, o que onerou o fluxo de caixa da atividade.

A produção de leite é mecanizada, com uso de ordenhadeira, sendo realizada duas vezes ao dia, logo no início da manhã e ao final da tarde.

$\mathrm{Na}$ gestão administrativa e financeira, o produtor iniciou com a realização de anotações diárias das atividades desenvolvidas na propriedade, utilizando uma apostila para controle. Todas as atividades de manejo do rebanho (produtivo, nutricional, reprodutivo e sanitário), bem como as despesas realizadas e as receitas obtidas foram registradas diariamente.

A coleta de dados é de suma importância no processo de análise, sendo necessário o acompanhamento do registro dos gastos realizados para que se tenha uma análise confiável e que represente a situação financeira da atividade. A partir de visitas mensais e a orientação técnica, foram feitos levantamentos do sistema de produção, de acordo com a gestão realizada pelo produtor. Em planilhas eletrônicas (MS-Excel ${ }^{\circledR}$ ), foram organizadas as informações do sistema de produção mensalmente. Os dados zootécnicos e financeiros da atividade foram coletados e dispostos em um horizonte de cinco anos, entre os anos de 2011 e 2015. Os valores imobilizados na propriedade, como a área, as instalações e benfeitorias, foram ajustados a uma taxa de $35,3 \%$ ao ano.

\subsection{Método}

Considerando todos os itens de produção levantados na atividade, promoveuse a classificação deles em dois grandes grupos (receitas e despesas), considerados como de extrema importância para a exploração da atividade leiteira. No grupo Receitas, foram considerados os valores monetários obtidos a partir da venda de animais, do leite produzido, dos serviços prestados e da venda de reciclados (sacos de ração e adubo). No grupo Despesas, foram consideradas as compras de insumos, 
Análise da viabilidade econômica e financeira da produção de leite em propriedade familiar: estudo de caso do Rancho Pacheco, RJ Mirella Suhett Tito, Afonso Aurélio de Carvalho Peres

compra de animais, gastos com manutenções de benfeitorias, bem como máquinas e implementos agrícolas, também com pagamento de mão de obra, impostos, medicamentos e outros itens essenciais à manutenção da produção.

$\mathrm{Na}$ análise dos dados, foi construído um fluxo de caixa e, a partir deste, calculados os indicadores econômicos de rentabilidade Valor Presente Líquido (VPL) e Taxa Interna de Retorno (TIR), segundo a metodologia proposta por Blank e Tarquin (2008).

No cálculo do VPL, consideraram-se quatro taxas de desconto que foram aplicadas sobre o fluxo de caixa líquido mensal, sendo de 2, 4, 6 e 8\% ao ano. As taxas de desconto foram escolhidas, considerando uma taxa mínima de atratividade (TMA) de $7,79 \%$ ao ano, valor este referência aos rendimentos médios obtidos pela caderneta de poupança no ano de 2015 (ANBIMA, 2018). Durante o período de estudo, compreendido entre os anos de 2011 e 2015, o rendimento médio obtido com a caderneta de poupança foi de $6,87 \%$ a.a. (ANBIMA, 2018).

A fim de identificar os itens de produção que mais exerceram influência nos resultados dos indicadores, realizou-se a Análise de Sensibilidade, conforme metodologia proposta por Buarque (1991). Nessa análise, cada item do fluxo de caixa da atividade foi estudado de forma individual, observando-se o impacto negativo que realizou sobre o fluxo de caixa, sempre na condição desfavorável ao produtor. Essa técnica indicou como o VPL variou em relação à mudança do valor de algum determinado item do fluxo de caixa, mantendo-se os valores dos outros itens constantes, promovendo um acréscimo em dez pontos percentuais, quando o item fosse enquadrado nas despesas e uma diminuição em dez pontos percentuais, quando o item fosse enquadrado nas receitas. Segundo Buarque (1991), mediante a análise de sensibilidade, pode-se determinar quais elementos devem ser estudados mais profundamente, permitindo conhecer a importância de cada variável sobre 0 desempenho do projeto.

Como as empresas estão sujeitas a mudanças cada vez mais frequentes no mercado, a análise de sensibilidade permite identificar onde são exigidas tomadas de 
Análise da viabilidade econômica e financeira da produção de leite em propriedade familiar: estudo de caso do Rancho Pacheco, RJ Mirella Suhett Tito, Afonso Aurélio de Carvalho Peres

decisões eficientes e pontuais para reduzir custos e as perdas, resultando no aumento da produtividade e reduzir o risco econômico-financeiro da atividade. Analisar o risco da produção pode ser uma alternativa que maximize as oportunidades de negócios. O risco está subjetivamente associado à probabilidade de um evento não ocorrer conforme o previsto, de forma a prejudicar o resultado esperado. Na realização da análise de risco, adotou-se o método de Monte Carlo (MMC), seguindo a metodologia proposta por Noronha (1981). Os modelos de simulação probabilísticos tiveram sua origem no MMC e têm como foco simulações de fenômenos aleatórios, introduzindo a análise de riscos, incorporando as variáveis ambientais e, consequentemente, os elementos de incerteza inerentes (Nascimento \& Zucchi, 1997). No método de Monte Carlo, diversas simulações foram realizadas, onde, em cada uma delas, foram gerados valores aleatórios para o conjunto de variáveis de entrada (valores mínimo, médio e máximo) e parâmetros do modelo que estão sujeitos a incerteza. $O$ conjunto de variáveis foi escolhido a partir da análise de sensibilidade, sendo considerados dez itens que apresentaram as maiores variações nos indicadores econômicos de rentabilidade. Tais valores aleatórios gerados seguiram as distribuições de probabilidade específicas que foram identificadas ou estimadas previamente.

\section{RESULTADOS E DISCUSSÃO}

Toda estrutura de qualquer propriedade destinada à produção agropecuária consiste em um conjunto de características próprias e únicas, cujos fatores a serem considerados devem ser avaliados de uma forma global e interativa, entendendo e criando oportunidades para a disponibilidade dos recursos produtivos: terra, capital e mão de obra. Assim, o produtor consegue promover a expansão do seu sistema de produção. Quando planejada corretamente, a atividade tende a alcançar as metas propostas e a promover o crescimento e desenvolvimento do setor em que está inserida. Os levantamentos de dados realizados permitiram diagnosticar a realidade da propriedade e auxiliar na estruturação das ações necessárias para a elaboração e 
Análise da viabilidade econômica e financeira da produção de leite em propriedade familiar: estudo de caso do Rancho Pacheco, RJ Mirella Suhett Tito, Afonso Aurélio de Carvalho Peres

realização de uma análise econômica que será responsável por apresentar os resultados que serão utilizados na tomada de decisão da atividade.

Por apresentar resultados positivos, a análise da viabilidade econômicofinanceira da propriedade demonstrou que a atividade leiteira explorada foi viável, financeiramente, a uma taxa de desconto de até $4 \%$ ao ano, entre os anos de 2011 e 2015 (Tabela 1).

Considerando-se a taxa mínima de atratividade de $6,87 \%$ ao ano, taxa esta equivalente ao rendimento médio obtido com a caderneta de poupança, entre os anos de 2011 e 2015 (ANBIMA, 2018), a atividade leiteira não se mostrou atrativa para o produtor, uma vez que a rentabilidade da propriedade foi de 5,30\% a.a., abaixo daquela obtida na opção de investimento, caderneta de poupança, considerada de baixo risco (Tabela 1). Em Castrolanda, PR, Silva (2006) encontrou resultado superior (9,66\%) de retorno do capital financeiro quando comparado aos resultados obtidos neste trabalho. O sistema de produção avaliado foi um sistema de semiconfinamento explorado na Cooperativa da Castrolanda, onde, segundo o autor, a rentabilidade obtida sobre o capital imobilizado indicou uma boa utilização dos fatores de produção: a terra e a mão de obra. 
Análise da viabilidade econômica e financeira da produção de leite em propriedade familiar: estudo de caso do Rancho Pacheco, RJ Mirella Suhett Tito, Afonso Aurélio de Carvalho Peres

Tabela 1

Valor Presente Líquido, em reais, e Taxa Interna de Retorno, em $\%$, do fluxo de caixa submetido às taxas de desconto de $2 \%, 4 \%, 6 \%$ e $8 \%$ ao ano, entre os anos de 2011 e 2015.

\begin{tabular}{lcc}
\hline & Taxa de desconto & VPL \\
\hline $2 \%$ & $\mathrm{R} \$ 111.106,72$ \\
$4 \%$ & $\mathrm{R} \$ 41.351,31$ \\
$6 \%$ & $-\mathrm{R} \$ 20.914,66$ \\
$8 \%$ & $-\mathrm{R} \$ 76.613,17$ \\
$\mathrm{TIR}$ & $5,30 \%$ \\
\hline
\end{tabular}

Nota. Fonte: o autor.

Nos dois primeiros anos de exploração da atividade, as despesas incorridas no processo produtivo superaram as receitas geradas, sendo necessárias ações emergenciais para alavancar a atividade e promover a melhoria dos indicadores de produção leiteira. Diante disso, construiu-se um plano de ações para os cinco anos de acompanhamento e avaliação da atividade leiteira, sendo recomendadas medidas para o curto e médio prazo. Dentre as principais ações adotadas no sistema de produção leiteira, destacaram-se:

- Melhoria da qualidade da pastagem com a substituição parcial do capim-braquiária pelo capim-giggs em áreas de melhor fertilidade do solo;

- Adequação da dieta oferecida às vacas em lactação, de acordo com as exigências nutricionais e nível de produção: e

- Descarte de vacas improdutivas e inservíveis ao sistema de produção leiteira.

Essas ações emergenciais começaram a apresentar resposta positiva a partir do quarto ano de acompanhamento. No fluxo de caixa, observou-se ainda que foram realizados investimentos na compra de equipamentos, maquinários e animais, os quais deram suporte para o desenvolvimento da produção leiteira entre os anos de 2013 e 2015. 
Análise da viabilidade econômica e financeira da produção de leite em propriedade familiar: estudo de caso do Rancho Pacheco, RJ Mirella Suhett Tito, Afonso Aurélio de Carvalho Peres

O estudo realizado por Peres et al. (2009) demonstrou que a adoção de sistemas de produção leiteira em pastagens cultivadas com uso de suplementação volumosa foi viável financeiramente a uma taxa de desconto de $8 \%$ ao ano. A rentabilidade financeira obtida para os diferentes sistemas de produção destinados à pecuária leiteira variou entre $8,46 \%$ e $11,91 \%$ ao ano, dependendo da alimentação volumosa oferecida. No Rancho Pacheco, a rentabilidade obtida foi inferior àquela encontrada pelos autores que analisaram três sistemas de produção leiteira em pastagem de capim-mombaça, com suplementação volumosa no período outonoinverno. Essa condição pode ser explicada pelo investimento realizado pelo proprietário na melhoria da qualidade da pastagem com a substituição da forrageira atual e pela substituição das vacas improdutivas, o que resultará na melhoria dos indicadores zootécnicos de produção, ao longo do tempo, devido à melhoria do valor nutritivo da alimentação ofertada aos animais, bem como ao aumento da produção individual das vacas adquiridas.

Os itens de maior influência nos resultados dos indicadores econômicos foram submetidos a uma variação de preços de mercado, de forma a caracterizar seu comportamento mediante a desvalorização de sua remuneração. A taxa aplicada à desvalorização foi de 10\%, sempre no sentido desfavorável à atividade, ou seja, quando se tratou de receita, promoveu-se um decréscimo na arrecadação e quando se tratou de despesa, promoveu-se um aumento no dispêndio de capital financeiro. $\mathrm{O}$ item de maior impacto econômico sobre os indicadores econômicos de rentabilidade da propriedade foi o investimento realizado na aquisição de terras para a exploração da atividade leiteira (Tabela 2 ). 
Análise da viabilidade econômica e financeira da produção de leite em propriedade familiar: estudo de caso do Rancho Pacheco, RJ Mirella Suhett Tito, Afonso Aurélio de Carvalho Peres

Tabela 2

Itens de maior influência sobre os resultados do indicador econômico de rentabilidade (VPL), por ordem decrescente, em reais.

\begin{tabular}{lc}
\hline \multicolumn{1}{c}{ Item } & Valor \\
\hline Valor do investimento realizado na compra da terra & $-\mathrm{R} \$ 49.941,00$ \\
Preço do leite recebido pelo produtor & $-\mathrm{R} \$ 26.679,75$ \\
Valor do investimento realizado na aquisição do rebanho & $-\mathrm{R} \$ 5.581,55$ \\
Valor do pró-labore & $-\mathrm{R} \$ 3.651,21$ \\
Valor de compra do veículo & $-\mathrm{R} \$ 3.494,23$ \\
Preço de compra do farelo de soja para ração animal & $-\mathrm{R} \$ 3.342,32$ \\
Preço de compra do fubá para ração animal & $-\mathrm{R} \$ 3.275,93$ \\
Pagamento da prestação dos animais & $-\mathrm{R} \$ 2.864,65$ \\
Preço de compra da polpa cítrica para ração animal & $-\mathrm{R} \$ 2.194,13$ \\
Preço de compra do combustível para o veículo & $-\mathrm{R} \$ 1.709,97$ \\
\hline
\end{tabular}

Nota. Fonte: o autor.

$\mathrm{Na}$ pecuária leiteira, é de conhecimento que a atividade necessita de um elevado valor monetário para investimento, onde o produtor imobiliza grande parte do capital financeiro na aquisição de área para explorar a atividade. Nessa condição, é preciso que a atividade apresente bons indicadores zootécnicos de produção para que o produtor possa obter uma rentabilidade atrativa do investimento realizado e, ainda, promova a valorização do patrimônio que adquiriu, pois a exploração de forma desordenada pode resultar na desvalorização e no sucateamento, levando-o a sérios prejuízos financeiros conforme relatado por Ferrazza, Lopes, Bruhn e Moraes (2015), quando avaliaram a produção leiteira utilizando mão de obra familiar e mão de obra mista. A fim de evitar essa condição de exploração, é preciso maximizar o uso das áreas agrícolas e garantir que os animais do rebanho apresentem o máximo potencial genético para a produção.

O segundo item de produção de maior importância para a atividade foi o preço pago pela cooperativa ao produtor no momento da comercialização do leite. No 
Análise da viabilidade econômica e financeira da produção de leite em propriedade familiar: estudo de caso do Rancho Pacheco, RJ Mirella Suhett Tito, Afonso Aurélio de Carvalho Peres

mercado de lácteos, a política de preços é pautada na quantidade produzida e na qualidade da matéria-prima fornecida e, em muitos casos, quem determina a política de preços são as empresas beneficiadoras de leite. O produtor rural dificilmente consegue influenciar na determinação do preço final do leite e, ainda, segundo Vilela, Leite e Resende (2002), o elevado custo de produção é um dos grandes entraves ao progresso do setor, o qual, aliado aos decréscimos do preço de comercialização do leite, explicaria a baixa rentabilidade obtida por litro de leite produzido. Devido a isso, o produtor deve realizar um planejamento da produção, adotando medidas de manejo que beneficiem a produção individual das vacas, como, por exemplo, o correto fornecimento da alimentação concentrada e volumosa, atendendo as exigências nutricionais diárias das vacas em produção. Outra medida é o controle reprodutivo e sanitário do rebanho, garantindo bons indicadores reprodutivos como a redução do intervalo de partos e não permitir que a presença de parasitas acometa o bem-estar animal e comprometa a produção das vacas. Segundo Sant'Anna (2000), para se obter um aumento na produção leiteira, faz-se necessário maior controle de doenças e parasitas no rebanho, aliado ao fornecimento de uma alimentação balanceada que atenda as exigências nutricionais diárias do rebanho. De acordo com os autores, outros fatores são de extrema importância, como a eficiente higienização de instalações e equipamentos, bem como o potencial genético dos animais para a produção de leite. Esse resultado também corrobora aquele encontrado por Peres et al. (2009), em que os autores observaram que o preço de comercialização do leite foi o item de maior influência sobre os resultados dos indicadores econômicos em sistemas de produção leiteira para vacas em pastagem cultivada de capim-mombaça.

Para alcançar um bom preço final no $\mathrm{kg}$ de leite produzido, uma alternativa é a adoção de duas estações de monta para o rebanho leiteiro, onde no manejo reprodutivo das vacas, seja considerado que o período de parição ocorra antes do período outonoinverno para que, nesta época, tenha-se maior produção leiteira, visando ao período de baixa oferta do produto nas empresas captadoras de leite, o que promove uma melhor remuneração no leite produzido. Porém, aliado a essa estratégia, recomenda-se um 
Análise da viabilidade econômica e financeira da produção de leite em propriedade familiar: estudo de caso do Rancho Pacheco, RJ Mirella Suhett Tito, Afonso Aurélio de Carvalho Peres

planejamento da alimentação do rebanho para este período, em que se observa uma baixa quantidade disponível de alimentação volumosa nas pastagens, sendo então recomendado o aumento da produção forrageira e sua conservação no período primavera-verão anterior ao período outono-inverno. Assim, pode-se obter uma maior uniformidade na produção de leite ao longo do ano ou, ainda, com maior produção para o período, em que se observa a melhor remuneração pelo leite produzido. Para Cóser e Pereira (2001), o uso de forrageiras tropicais cultivadas para o corte e pastejo beneficiaram a produção de leite e apresentaram vantagens, quando em sistemas confinados. No caso da produção leiteira explorada por pequenos investidores, com animais pouco especializados, estas devem ser oferecidas na forma de pastagem como base da alimentação, observando assim menores investimentos e custo operacional de produção.

A alimentação animal baseada no fornecimento de ração concentrada (energéticos e protéicos) para o rebanho é um item de grande impacto financeiro na atividade e de extrema importância para garantir a produção leiteira das vacas. $\mathrm{Na}$ análise de sensibilidade (Tabela 2), observou-se que três ingredientes (farelo de soja, fubá e polpa cítrica) se apresentaram como itens de grande influência nos resultados econômicos da atividade. Qualquer variação de preços na aquisição desses insumos impacta significativamente nos resultados econômicos da atividade. O correto uso desses ingredientes na formulação da ração balanceada $e o$ atendimento às exigências nutricionais diárias do rebanho garantem a produção individual dos animais e ainda, maximizam a aplicação dos recursos financeiros disponíveis para a atividade leiteira. Em determinados períodos do ano em que se observa o aumento do preço de comercialização desses ingredientes, pode-se adotar o uso de eventuais substitutivos na composição da ração balanceada, porém ressalta-se a importância no fornecimento da alimentação que atenda a demanda nutricional dos animais, sem 0 comprometimento de seu potencial genético produtivo.

Tendo em vista a grande importância da alimentação do rebanho e da produção individual das vacas, que podem apresentar grandes variações nos preços de mercado, 
Análise da viabilidade econômica e financeira da produção de leite em propriedade familiar: estudo de caso do Rancho Pacheco, RJ Mirella Suhett Tito, Afonso Aurélio de Carvalho Peres

recomenda-se a adoção de planejamento e desenvolvimento de práticas que superem as expectativas quanto à boa nutrição animal e minimizar esse impacto financeiro gerado pelos concentrados, podendo ser adotada a alternância de pastagem nutritiva e de qualidade, com os devidos manejos de adubação e calagem, de forma a evitar processos erosivos no solo e degradação da pastagem. Nesta condição, promove-se o aumento no fornecimento de volumosos de qualidade e se reduz o uso de concentrados que apresentam maior custo de produção.

Toda atividade apresenta um risco econômico-financeiro, devendo este ser de conhecimento do produtor. Qualquer alteração no fluxo de caixa, diante das mudanças nos preços recebidos pelos produtos comercializados ou nos preços pagos pelos insumos necessários à atividade promove diminuição na rentabilidade financeira. $O$ risco econômico-financeiro da atividade leiteira, durante o período analisado, foi de $51,08 \%$, quando se considerou uma taxa de desconto de $4 \%$ a.a. (Tabela 3 ).

\section{Tabela 3}

Risco econômico-financeiro da atividade leiteira submetida às taxas de desconto de $2 \%, 4 \%, 6 \%$ e $8 \%$ ao ano, entre os anos de 2011 e 2015.

\begin{tabular}{|c|c|}
\hline Taxa de desconto & VPL \\
\hline $2 \%$ & $6,14 \%$ \\
\hline $4 \%$ & $51,08 \%$ \\
\hline $6 \%$ & $94,35 \%$ \\
\hline $8 \%$ & $99,91 \%$ \\
\hline
\end{tabular}

Nota. Fonte: o autor.

O risco econômico-financeiro da atividade leiteira foi classificado como alto para investimento, visto que a atividade apresentou $99,91 \%$ de ser inviável financeiramente, a uma taxa de desconto de $8 \%$ a.a., quando comparada à taxa mínima de atratividade média considerada neste trabalho, que foi da ordem de $6,87 \%$ para os rendimentos obtidos com a caderneta de poupança (ANBIMA, 2018) entre os anos de 2011 e 2015. 
Análise da viabilidade econômica e financeira da produção de leite em propriedade familiar: estudo de caso do Rancho Pacheco, RJ Mirella Suhett Tito, Afonso Aurélio de Carvalho Peres

Nessa condição, o produtor deve estar atento aos seus custos de produção e ao gerenciamento do dispêndio do capital financeiro, pois as alterações de preços ocorridas no mercado, frente aos principais itens de produção, podem tornar a atividade leiteira inviável no curto prazo. Para Sant'Anna (2000), as análises de riscos comprovaram que os valores gerados a cada alteração dos parâmetros "preço" e "volume" na produção leiteira podem gerar um risco financeiro na ordem de $42 \%$ de se obter resultados positivos e a probabilidade de se obter uma rentabilidade anual inferior a $12 \%$, devido à necessidade de se realizarem investimentos em tecnologia que possam contribuir com a qualidade do produto final. Oliveira, Noronha, Figueiredo e Silva (2007) observaram que a maioria dos produtores leiteiros não trabalhavam com inseminação artificial, bem como também não utilizavam a ordenha mecanizada para a produção leiteira. Ao adotarem essas tecnologias para melhoria da produção leiteira e dos indicadores zootécnicos de produção, os autores observaram que o risco econômico para investimento nesse sistema de produção leiteira, com produção diária de até 150 litros de leite, foi na ordem de 33,08\%, com uma rentabilidade inferior a 6\% a.a. Os resultados operacionais determinísticos evidenciaram uma tendência de descapitalização do pequeno produtor que, em função do baixo volume de produção leiteira, não conseguiria auferir lucro suficiente para reinvestir, ampliar e promover o crescimento de sua atividade.

\section{CONCLUSÕES}

O estudo demonstra que, para maior competitividade do produtor no mercado lácteo, é necessário que promova mudanças estratégicas de ação na propriedade, exigindo maior intensificação na administração e no gerenciamento da atividade, com a finalidade de garantir os padrões de qualidade do produto e a produtividade do rebanho. É necessário explorar ao máximo as tecnologias empregadas, visando ao aumento do volume de leite diário produzido, investindo na alimentação do rebanho. Avaliar financeiramente a implementação de tecnologias e mudanças no processo 
Análise da viabilidade econômica e financeira da produção de leite em propriedade familiar: estudo de caso do Rancho Pacheco, RJ Mirella Suhett Tito, Afonso Aurélio de Carvalho Peres

produtivo da pecuária leiteira é de extrema importância para auxiliar o produtor na sua tomada de decisão.

O sistema de produção leiteira é viável financeiramente durante o período de estudo, porém, apresenta baixa rentabilidade financeira, não sendo atrativa para investimento. Por apresentar um elevado valor financeiro imobilizado na aquisição das terras, a exploração produtiva dessas áreas deve ser maximizada, reduzindo a ociosidade, bem como os baixos indicadores produtivos por área explorada, o que classificou a atividade leiteira com alto risco econômico-financeiro, na condição analisada. O valor do investimento na compra da terra e na aquisição de animais são os itens de maior influência nos resultados dos indicadores econômicos, seguido pelo preço de comercialização do leite e pelo valor de compra dos ingredientes utilizados na alimentação concentrada.

Uma recomendação para minimizar o risco econômico-financeiro da atividade é promover a uniformidade na produção leiteira e garantir a quantidade mínima de leite fornecida à unidade captadora, o que pode ser justificado pela implantação de estação de monta em períodos de melhor remuneração do leite, garantindo o maior preço recebido.

\section{REFERÊNCIAS}

Altafin, I., Pinheiro, M. E. F., Valone, G. V., \& Gregolin, A. C. (2011). Produção familiar de leite no Brasil: um estudo sobre os assentamentos de reforma agrária no município de Unaí (MG). Revista Uni, 1(1), 31-49.

Araújo, M. J. (2007). Fundamentos de Agronegócios. São Paulo: Atlas.

ANBIMA - Associação Brasileira das Entidades dos Mercados Financeiro e de Capitais. Recuperado de http://www.ipeadata.gov.br/ExibeSerie.aspx?serid=31878\&Module=M. Acesso em: 24/maio/2018.

Batalha, M. O. (2009). Gestão Agroindustrial: grupos de estudos e pesquisas agroindustriais. Coord. Mário Otávio Batalha. São Paulo: Atlas. 
Análise da viabilidade econômica e financeira da produção de leite em propriedade familiar:

estudo de caso do Rancho Pacheco, RJ

Mirella Suhett Tito, Afonso Aurélio de Carvalho Peres

Blank, L., \& Tarquin, A. (2008). Engenharia Econômica. São Paulo, McGraw-Hill.

Buarque, C. (1991). Avaliação Econômica de Projetos: uma apresentação didática. Rio de Janeiro, Campus.

Campos, K. C., \& Piacenti, C. A. (2007, Julho). Agronegócio do leite: cenário atual e perspectivas. Anais do Congresso da Sociedade Brasileira de Economia, Administração e Sociologia Rural, Londrina, PR, Brasil, 45.

Carvalho, F. de M., Ramos, E. O., \& Lopes, M. A. (2009). Análise comparativa dos custos de produção de duas propriedades leiteiras no município de Unaí-MG, no período de 2003 e 2004. Revista Ciência e Agrotecnologia, 33 (Edição especial), $1705-1711$.

Cóser, A. C., \& Pereira, A. V. (2001). Forrageiras para corte e pastejo. Juiz de Fora, EMBRAPA.

EMBRAPA. (2017, Agosto). Indicadores: leite e derivados. Disponível em: $<$ https://ainfo.cnptia.embrapa.br/digital/bitstream/item/167783/1/Cnpgl-2017Indicadores-Leite-69.pdf> Acesso em: 05/jun./2018.

Ferrazza, R. A., Lopes, M. A., Bruhn, F. R. P., \& Moraes, F. (2015). Índices de desempenho zootécnico e econômico de sistemas de produção de leite com diferentes tipos de mão de obra. Ciência e Animal Brasileira, 16(2), 193-204.

Gomes, S. T. (2003). O Agronegócio do Leite. SEBRAE - MG/FAEMG. Belo Horizonte, MG. 99p.

Guimarães Neto, O. (2008). Introdução e Conceito de Custos. Análise de Custos. Curitiba: IESDE Brasil S.A., 7-12p.

IBGE - Instituto Brasileiro de Geografia e Estatística. (2016). Produção da pecuária municipal. Rio de Janeiro. 44, 1-51.

Lima Júnior, A. C. S. (2014, Julho). Brasil leiteiro de Sul a Norte. Recuperado de: $<$ https://www.milkpoint.com.br/arquivos/EBOOK-BRASIL-LEITEIRO.pdf> Acesso em: 08/jun./2018.

Nascimento, A. M., \& Zucchi, A. L. (1997). Modelos de simulação. São Paulo, SP. Monografia. Faculdade de Economia, Administração e Contabilidade. Universidade de São Paulo - USP, 40p. 
Análise da viabilidade econômica e financeira da produção de leite em propriedade familiar:

estudo de caso do Rancho Pacheco, RJ

Mirella Suhett Tito, Afonso Aurélio de Carvalho Peres

Noronha, J. F. (1981). Projetos agropecuários: administração financeira, orçamento e viabilidade econômica. São Paulo, Atlas.

Oliveira, E. R. O., Noronha, J. F., Figueiredo, R. S., \& Silva, R. P. J. (2007). Estudo de viabilidade econômica e risco para sistemas de bovinocultura de leite em Piracanjuba, GO. Revista de Política Agrícola, 16(3), 49-57.

Peres, A. A. C., Vásquez, H. M., Souza, P. M., Coelho da Silva, J. F., Villela, O. V., \& Santos, F. C. (2009). Análise financeira e de sensibilidade de sistemas de produção de leite em pastagem. Revista Brasileira de Zootecnia, 38(10), 2072-2078.

Resende, J. C. de. (2010). Determinantes de lucratividade em fazendas leiteiras de Minas Gerais. Lavras, MG. (Tese de Doutorado). Universidade Federal de Lavras UFLA.

Sant'Anna, D. D. (2000). Análise de viabilidade e risco de implantação da coleta de leite a granel. (Dissertação de Mestrado). Universidade Federal de Viçosa - UFV.

Silva, H. A. (2006). Resultados econômicos de sistema de produção de leite com diferentes níveis tecnológicos na Cooperativa Castrolanda, Castro, PR. Trabalho apresentado ao Prêmio Extensão Rural - EMATER, Curitiba, PR, Brasil, 2. Recuperado de: http://www.emater.pr.gov.br/arquivos/File/Biblioteca_Virtual/Premio_Extensao_Rural /2_Premio_ER/26_Res_Ecs_Sist_Prod_Leite.pdf> Acesso em: 08/jun./2018.

Silva, R. A. G. da (2013). Administração Rural: teoria e prática. Curitiba: Juruá.

Slack, N., Chambers, S., Johnston, R., \& Betts, A. (2008). Gerenciamento de operações e de processos: princípios e práticas de impacto estratégico. Bookman Editora.

Vilela, D., Leite, J. L. B., \& Resende, J. C. (2002). Políticas para o leite no Brasil: passado, presente e futuro. Anais do Sul-Leite: Simpósio sobre Sustentabilidade da Pecuária Leiteira na Região Sul do Brasil, Maringá, PR, Brasil, 1.

Zoccal, R., \& Souza, A. D. (2005). Produção de leite na agricultura familiar. Juiz de Fora, EMBRAPA.

Data de Submissão: 13/06/2018

Data de Aceite: 16/09/2019 